\title{
Experimental Verification to Estimate Ground Thermal Conductivity Using Spiral Coil Type Ground Heat Exchangers
}

\author{
Seok Yoon, Min Jun Kim, Gyu Hyun Go and Seung Rae Lee \\ Department of Civil and Environmental Engineering, Korean Advanced Institute of Science and Technology (KAIST), Daejeon \\ 305-701, South Korea
}

\begin{abstract}
This paper presents an experimental study on the evaluation of thermal response of a spiral coil type GHE (ground heat exchanger). This GHE was installed on partially saturated landfill ground that was composed of silt and clay in the runway area of Incheon International airport. TRT (thermal response test) was conducted for more than 65 hours under continuous operation conditions. Ground thermal conductivity was derived based on line source theory, which has usually been found to be appropriate for line type GHEs such as $\mathrm{U}, \mathrm{W}$ and $2 \mathrm{U}$ types. A reasonable method to derive ground thermal conductivity using the infinite line source theory for a spiral coil type GHE was introduced. Ground thermal conductivity from the TRT using spiral coil type GHE was compared with those from the analytical equivalent model of ground thermal conductivity.
\end{abstract}

Key words: Ground thermal conductivity, ground heat exchanger, thermal response test, spiral coil.

\section{Introduction}

The need for renewable energy sources is constantly increasing with the advent of global warming and depletion of fossil energy. Geothermal energy has great potential to provide directly usable energy, especially in connection with ground sources or GCHP (ground-coupled heat pump) systems. GCHP systems use the ground as a heat source as it provides a relatively constant temperature. They release heat energy in summer while they absorb heat energy in winter. Agriculture also can use a GCHP system for heating and cooling of a greenhouse. Since heat demands from greenhouses are more complex than those for residence buildings, greenhouses are strongly affected by weather conditions. For that reason, GCHP systems for greenhouses require accurate estimation of ground thermal properties. GCHP systems can be categorized into open or closed

Corresponding author: Seung Rae Lee, Ph.D., Prof., research fields: slope stability analysis and geothermal energy utilization. E-mail: srlee@kaist.ac.kr. systems. Open systems exchange heat to/from aquifer water, closed systems exchange heat to/from the ground by circulating fluid in heat exchange pipes. Closed systems can be largely divided into vertical and horizontal types. A horizontal system requires the installation of a large volume of GHEs (ground heat exchangers) at shallow depth, necessitating a large land area. A vertical system has high initial construction costs as a borehole of up to tens or hundreds of meters has to be installed. As an alternative, the application of energy piles, which utilize piles under a raft foundation, has recently been expanded [1]. This system has the advantage of affordable initial investment costs, it does not require additional construction costs during the construction process. Compared to conventional vertical type systems, the energy pile has a larger diameter and shorter length. In Korea, most energy piles have relatively short length of less than $20 \mathrm{~m}$, because of the shallow depth of the bedrock location. For that reason, to compensate for the shallow installation 
depth of the energy pile, a spiral coil type GHE can be used to enhance the heat efficiency because such a device can increase the heat exchange area compared to $\mathrm{U}$ and $\mathrm{W}$ type GHEs [2].

Ground thermal conductivity is one of the most important factors in the design process of GCHP systems in the conventional vertical GHEs, as well as in energy piles [3]. The value of ground thermal conductivity can be derived simply by applying the infinite line source model with field TRT (thermal response test) results. However, it is not accurate to use the infinite line source model in spiral coil type GHEs [4]. Therefore, different kinds of analytical models adequate for spiral coil type GHEs have been introduced. These models are very complicated and make it inconvenient to derive the ground thermal conductivity. Accordingly, this paper introduces a simple method to derive the ground thermal conductivity from TRT results conducted in spiral coil type GHEs. The results were also compared with results for real ground thermal conductivity.

\section{Theoretical Background}

In GHE systems, heat is extracted from or released to the surrounding ground through a circulating fluid. The heat transfer mechanism of a ground heat exchanger is quite complex and conjugated because of the various heat transfer mechanisms involved inside and outside the GHEs. Soil is a multiple phase system involving complex heat transfer mechanisms, however, heat transfer in soils occurs mainly through conduction [1], whereby energy is passed from one region of a medium to another by molecular transfer. According to Fourier's law, the heat flux through an arbitrary area $(A)$ during time $(t)$ can be written as

$$
q=\frac{Q}{A t}=\frac{\dot{Q}}{A}=-\lambda \frac{\partial T}{\partial x}
$$

where, $\lambda$ is the thermal conductivity and $\partial T / \partial x$ is the temperature gradient. The GHE can be treated as a line source considering that the radius of a borehole is much smaller than its length. The change in ground temperature at a distance $(r)$ from the line source after time $(t)$, and the constant heat injection rate per active length of the borehole $(q)$ can be approximated using the infinite line source model. The above equation can be applied to conditions in which $L$ (heat source length) $/ D$ (heat source diameter) is larger than 25-30 [5].

$$
T_{(r, t)}-T_{(t=0)}=\frac{q}{4 \pi \lambda}\left(\ln \left(4 \alpha t / r^{2}\right)-\gamma\right)
$$

In this equation, $\gamma$ is the Euler constant, which is normally 0.5772 , and $\alpha$ is the ground thermal diffusivity. The error can be up to a maximum of $2.5 \%$ for $\alpha t / r^{2} \geq 20$ and $10 \%$ for $\alpha t / r^{2} \geq 5[6,7]$. By picking two points on the linear part of the curve of mean circulating fluid temperature, i.e., the average fluid temperature between the inlet and outlet-time in a semi-natural logarithmic scale under steady state conditions, the ground thermal conductivity can be approximately estimated using the following equation:

$$
\lambda=\frac{Q}{4 \pi L}\left(\frac{\ln t_{2}-\ln t_{1}}{T_{f, a v, 2}-T_{f, a v, 1}}\right)
$$

Soil in the ground is normally non-homogeneous, especially in the vertical direction along GHEs. An analytical equivalent model for multi-layered soil can be achieved using the following equation [8]:

$$
\lambda_{e q}=\frac{\left(h_{1} \lambda_{1}+h_{2} \lambda_{2}+h_{3} \lambda_{3}\right)}{h_{1}+h_{2}+h_{3}}
$$

\section{Experimental Setup}

A spiral coil GHE (Fig. 1) in the general vertical type system was installed in a partially saturated landfilled runway area of Incheon International Airport in South Korea. The spacing of the coil is $5 \mathrm{~cm}$, the coil diameter is $28 \mathrm{~cm}$, and the vertical depth is $30 \mathrm{~m}$. Polybutylene pipe (inner/outer diameter of pipe $=0.016 / 0.02 \mathrm{~m}$ ) was used for the GHEs, and bentonite grout was poured into the borehole. Fig. 2 shows the construction process of the vertical GHEs in the field. The ground was composed of silt, clay, 

Using Spiral Coil Type Ground Heat Exchangers

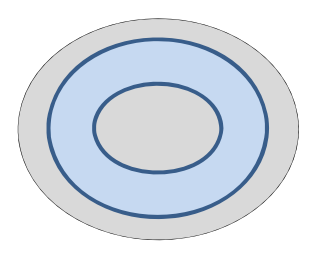

Co il type

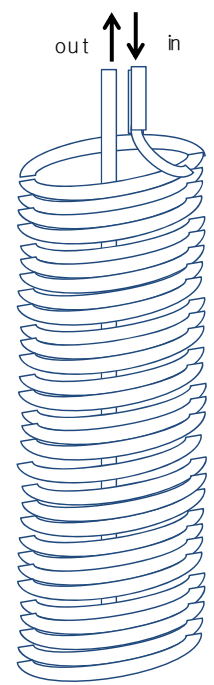

Fig. 1 Diagram of spiral coil type GHE.

weathered granite soil and weathered rock. Ground water level was $3.5 \mathrm{~m}$ below the top of the embedded borehole. The SPT (standard penetration test) $\mathrm{N}$ value was $9 / 30-33 / 30$ in the partially saturated landfill ground, and weathered rock appeared $30 \mathrm{~m}$ below the ground level. The average void ratio was 0.95 and water content was between 30\%-35\%. The thermal conductivity of the landfill soil was measured using a
TP-08 device (Hukseflux Thermal Sensors Inc.), based on the transient hot-wire method. Soil was remolded to have the same void ratio and water content as those of the construction site. The thermal conductivity of the silt-clay in the landfill area below the ground water table was measured and found to be $2.3 \mathrm{~W} / \mathrm{m} \cdot \mathrm{K}$. Since not all the layered soils were sampled, the thermal conductivity of the weathered granite soil was estimated to be around $2.4 \mathrm{~W} / \mathrm{m} \cdot \mathrm{K}$ from the fitted model suggested by Park et al. [2] in order to derive the thermal conductivity of Korean granite soil. Table 1 shows basic ground thermal properties. The weighted average ground thermal conductivity value, considering each layer's ground depth, was found to be around $2.10 \mathrm{~W} / \mathrm{m} \cdot \mathrm{k}$ using Eq. (4).

\section{Results and Discussion}

Constant heat flux was applied to the water tank using an electric heater, and TRT was conducted until a steady state condition was attained. Temperatures of water at the inlet and the outlet were monitored during

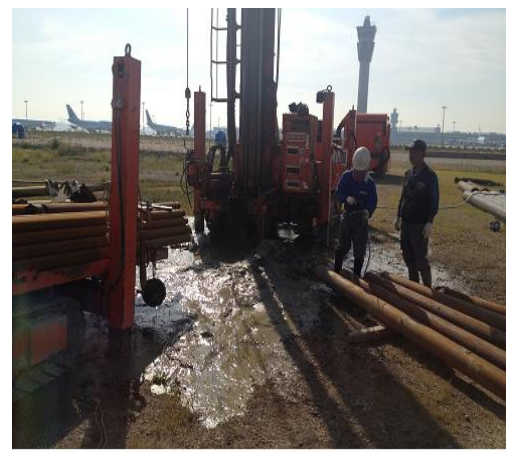

(a) Drilling of borehole

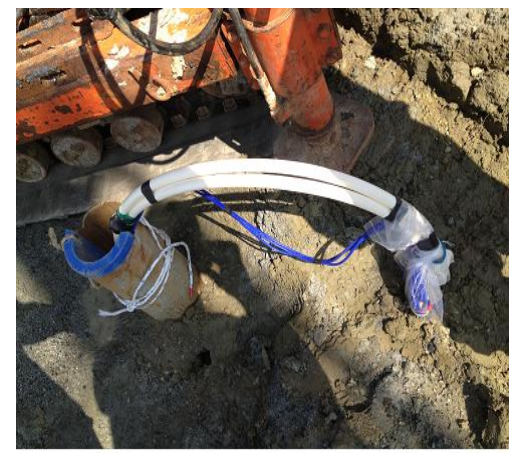

(b) Installation of GHE

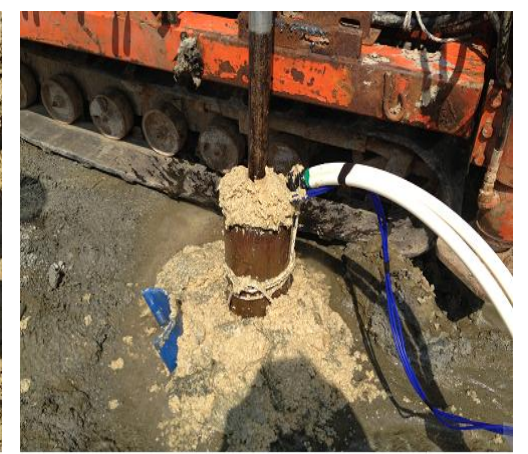

(c) Bentonite grouting

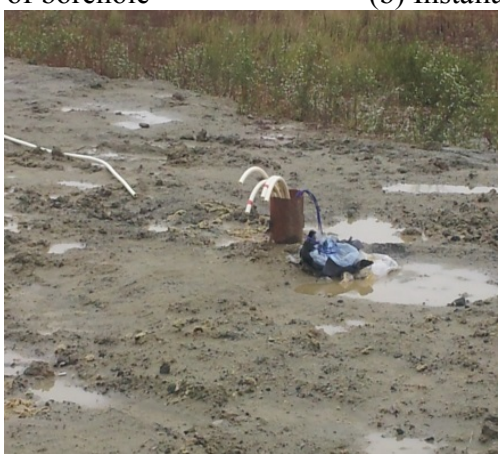

(d) Curing of grout

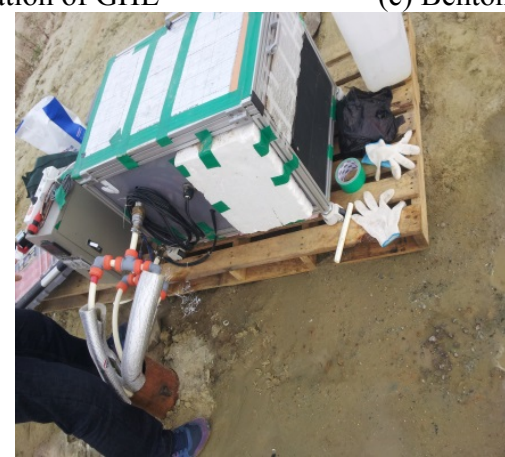

(e) Connection to TPT equipment

Fig. 2 Construction processes of GHE. 
Table 1 Basic ground thermal properties.

\begin{tabular}{llll}
\hline Materials & Thermal conductivity $(\mathrm{W} / \mathrm{m} \cdot \mathrm{K})$ & Specific heat capacity $(\mathrm{J} / \mathrm{kg} \cdot \mathrm{K})$ & Density $\left(\mathrm{kg} / \mathrm{m}^{3}\right)$ \\
\hline Soil 1 & 0.21 & 800 & 1,600 \\
Soil 2 & 2.30 & 1,300 & 2,100 \\
Soil 3 & 2.40 & 1,280 & 2,140 \\
\hline
\end{tabular}

the test, and the flow rate was also measured at the outlet. Generally, in the case of a closed vertical type system, the thermal response test has to be conducted for over $48 \mathrm{~h}$ until the steady state condition is attained. However, in this experiment, the temperature of the circulating water only reached its normal state after $60 \mathrm{~h}$, and hence the test was conducted for $65 \mathrm{~h}$. Since the heat transfer of the spiral coil type GHE occurred easily in comparison with those of the $U$ and W type GHEs, it took more time to reach the steady state. Heat-free water circulation was performed for $30 \mathrm{~min}$ to equalize the soil and circulating fluid temperature. The initial temperature of the soil due to the heat free water circulation was $16.14{ }^{\circ} \mathrm{C}$, the temperature distribution was between $16.14-31.34{ }^{\circ} \mathrm{C}$ during the TRT. The average temperature difference between the inlet and the outlet was $5.6{ }^{\circ} \mathrm{C}$. With the temperature value and the slope of $\Delta T / \Delta \ln t$, it was possible to evaluate the ground thermal conductivity using Eq. (3), the value was found to be $2.17 \mathrm{~W} / \mathrm{m} \cdot \mathrm{K}$. This value is very similar to the equivalent ground thermal conductivity derived using Eq. (4) at a depth of $30 \mathrm{~m}$ below the surface. As the value of $L$ (heat source length) $/ D$ (heat source diameter) is almost 100 , Eq. (3) can also be used to derive the ground thermal conductivity in the spiral coil type GHE. However, if the temperature values at just $48 \mathrm{~h}$ are used, the ground thermal conductivity, estimated using Eq. (3), is around $1.86 \mathrm{~W} / \mathrm{m} \cdot \mathrm{K}$. This is because TRT did not reach the steady state condition within $48 \mathrm{~h}$. Therefore, the estimated ground thermal conductivity was not appropriate.

\section{Conclusions}

An experimental system for TRT in a spiral coil type GHE was established in the field. TRT was performed for the spiral coil type GHE in a partially saturated landfilled runway area of Incheon International Airport in South Korea. As the value of $L$ (heat source length) $/ D$ (heat source diameter) is almost 100, the infinite line source model was applied to derive the ground thermal conductivity from the TRT results for the spiral coil type GHE. The estimated ground thermal conductivity was 2.17 $\mathrm{W} / \mathrm{m} \cdot \mathrm{K}$, this value was very similar to that derived using the analytical equivalent model of the ground thermal conductivity at a ground depth of $30 \mathrm{~m}$. It was concluded that the ground thermal conductivity can be reasonably derived from TRT in a spiral coil type GHE. However, TRT should be continued until a steady state condition is attained. After that, the infinite line source model can be applied to the TRT results. It should be considered that TRT in a spiral coil type GHE should not be performed under the same conditions as those used for $\mathrm{U}$ and $\mathrm{W}$ type GHEs.

\section{Acknowledgments}

This research was partially supported by the 2011 Construction Technology Innovation Project (11 Technology Innovation E04) under the Korea Agency for Infrastructure Technology Advancement and by the basic research project under the National Research Foundation of Korea.

\section{References}

[1] H. Brandl, Energy foundation and other thermo-active ground structures, Geotechniques 56 (2) (2006) 81-122.

[2] H. Park, S.R. Lee, S. Yoon, J.C. Choi, Evaluation of thermal response and performance of PHC energy pile: Field experiments and numerical simulation, Applied Energy 103 (2012) 12-24.

[3] S. Yoon, S.R. Lee, G.D. Oh, D.S. Lee, Integrity of optical fiber sensor for measurement of ground thermal 


\section{Using Spiral Coil Type Ground Heat Exchangers}

conductivity, in: Proceeding of 6th International Workshop on Asian-Pacific Network of Centers for Research in Smart Structure Technology, Dalian, China, 2011.

[4] P. Cui, X. Li, Y. Man, Z. Fang, Heat transfer analysis of pile geothermal heat exchangers with spiral coils, Applied Energy 88 (2011) 4113-4119.

[5] J.H. Blackwell, A.D. Misener, Approximate solution a transient heat flow problem, Proc. Phys. Soc. A. 64 (1951) 1132-1133.

[6] P. Roth, A. Georgiev, A. Busso, E. Barraza, Firstinsitu determination of ground and borehole thermal properties in Latin America, Renewable Energy 29 (2004) 1947-1963.

[7] G. Florides, S. Kalogirou, First in situ determination of the thermal performance of an U-pipe borehole heat exchanger in Cyprus, Applied Thermal Engineering 28 (2008) 157-163.

[8] S. Yoon, S.R. Lee, G.H. Go, J.F. Xue, H.G. Park, D.W. Park, Thermal transfer behavior in two types of W-shaped ground heat exchangers installed in multilayer soils, Geomechanics and Engineering 6 (1) (2014) 79-98. 